Recebido em 12/2013. Aceito para publicação em 09/2014.

\title{
LEVANTAMENTO EPIDEMIOLÓGICO DE INFECÇÃO POR ACINETOBACTER SPP EM AMOSTRAS DE HEMOCULTURAS DE UM LABORATÓRIO DE SÃO JOSÉ DOS CAMPOS
}

\section{EPIDEMIOLOGICAL STUDY OF ACINETOBACTER SPP INFECTION IN BLOOD CULTURES OF A LABORATORY IN SÃO JOSÉ DOS CAMPOS}

\author{
Vânia Waleska Sousa da Cunha ${ }^{1}$ \\ Antonio Carlos Victor Canettieri² \\ Renata de Cassia Bernardes ${ }^{3}$
}

\begin{abstract}
Resumo: A presença de infecções na corrente sanguínea representa uma grave complicação na situação de pacientes críticos, podendo aumentar os riscos de morbidade e mortalidade, sendo a hemocultura um importante recurso no diagnóstico do agente microbiano. Entre as bactérias causadoras de bacteriemia, encontramos, frequentemente, a Acinetobacter spp, sendo um patógeno de grande importância clínica devido ao aumento de sua frequência como causa de infecções hospitalares e, também, por, normalmente, apresentar multirresistência aos agentes antimicrobianos de prática clínica. O presente estudo teve como finalidade o levantamento epidemiológico de infecções em hemoculturas causadas pelo gênero Acinetobacter spp em pacientes internados, em hospitais de São José dos Campos-SP, demonstrando sua prevalência no munícipio. Os dados analisados foram fornecidos pelo sistema de um laboratório de análises microbiológicas e utilizados para o levantamento de infecções por Acinetobacter spp em hemoculturas, no período de agosto de 2012 a agosto de 2013. Foram avaliados 5.759 exames de hemocultura, com 1.019 resultados positivos, sendo que Acinetobacter baumannii foi identificada em 31 amostras, correspondendo ao sexto patógeno mais isolado (3,04\% das hemoculturas positivas). A. baumannii se tornou um patógeno de grande preocupação hospitalar, devido à sua crescente colonização nas Unidades de Tratamento Intensivo e sua multirresistência aos antimicrobianos.
\end{abstract}

Palavras-chave: Acinetobacter baumannii; levantamento epidemiológico; hemoculturas.

Abstract: The presence of bloodstream infections is a serious complication in critically ill patients, and may increase the risk of morbidity and mortality. Blood culture is important in the diagnosis of microbial agents. Among the bacteria causing bacteremia, Acinetobacter spp was often found, which is a pathogen of major clinical importance with high frequency of nosocomial infections and usually can be found with multidrug resistance to antimicrobial agents in clinical practice. The present study did an epidemiological survey of infections in blood cultures caused by Acinetobacter spp in patients hospitalized in São José dos Campos, SP, demonstrating the hospital incidence in the municipality. Data were provided by a microbiological laboratory, and it was used for determine incidence of Acinetobacter spp infections in blood cultures in the period August 2012 to August 2013. During the period studied by the survey, 5,759 blood culture tests were analyzed, with 1,019 positive results. Acinetobacter baumannii was found in 31 samples, being the sixth most isolated pathogen, and corresponded to $3.04 \%$ of positive blood cultures. A. baumannii has become an important hospital pathogen due to its increased colonization in intensive care units and its multidrug resistance to antimicrobial agents.

Keywords: Acinetobacter baumannii; epidemiological survey; blood cultures.

\footnotetext{
${ }^{1}$ Graduada em Biomedicina - Universidade do Vale do Paraíba - Univap, Brasil. E-mail: vania.waleska@hotmail.com. 2 Doutor em Biopatologia Bucal - Universidade Estadual Paulista Júlio de Mesquita Filho - Unesp, Brasil e Docente da Univap. E-mail: acanettieri@gmail.com.

${ }^{3}$ Especializada em Análises Clinicas de doenças Infecciosas - Universidade de Taubaté - Unitau, Brasil e Bióloga na Valeclin Laboratório de Análises Clínicas S/S Ltda, Brasil. E-mail: renatacbernardes@ig.com.br.
}

Revista Univap - revista.univap.br

São José dos Campos-SP-Brasil, v. 20, n. 36, dez.2014. ISSN 2237-1753 


\section{INTRODUÇÃO}

É de grande preocupação a presença de bactérias na corrente circulatória de pacientes internados em hospitais, pois se aumenta o risco de morbidade e mortalidade. As bacteriemias geralmente ocorrem pela penetração de micro-organismos, a partir de um foco primário de infecção, nos vasos linfáticos, chegando, posteriormente até o sangue; ou por uma via direta através de agulhas e cateteres (LEVY et al., 2004).

A bacteriemia pode ocorrer de uma forma discreta, em casos em que há o deslocamento de bactérias do intestino ou da gengiva para a corrente sanguínea; e o próprio organismo se encarrega de removê- las. Porém, em casos mais graves, há a formação de uma infecção na corrente circulatória, gerando uma sepse, na qual o paciente apresentará sintomas clínicos e necessitará de tratamento adequado (PORTER et al., 2009).

Para o diagnóstico do agente microbiano presente na corrente sanguínea, causador da infecção, o exame de hemocultura é muito utilizado, trazendo resultados satisfatórios (LEVY et al., 2004).

Acinetobacter spp é um cocobacilo Gram negativo, oxidase negativo, catalase positivo, não esporulado e com temperatura de crescimento entre 33 a $35^{\circ} \mathrm{C}$; pertencente à família Neisseriaceae. Atualmente, existem mais de 20 espécies de Acinetobacter conhecidas, porém o maior causador de infecções nas Unidades de Tratamento Intensivo é A. baumannii. A preocupação inicial com a Acinetobacter spp começou em 1991, quando se observou o primeiro relato de surto em hospitais na cidade de Nova York (RUNGRUANGHIRANYA; CHARURAT; TERMKIAT, 2005).

Atualmente, esse micro-organismo é considerado patógeno nosocomial em diversas partes do mundo, causando um aumento na mortalidade e morbidade, sendo atribuídos à bactéria seis casos de óbito em cada dez pacientes contaminados (LUZ, 2010). Há relatos da preferência bacteriana por ambientes quentes e úmidos, destacando-se, então, a sua importância em países que apresentam essa característica (RUNGRUANGHIRANYA; CHARURAT; TERMKIAT, 2005).

Acinetobacter spp apresenta grande facilidade para adquirir genes de resistência a uma ampla variedade de antimicrobianos e possui capacidade de sobrevivência em diversas condições ambientais, persistindo por tempos prolongados em superfícies, o que explicaria sua importância em infecções hospitalares (LUZ, 2010; ELIOPOULOS et al., 2008; FIGUEIREDO et al., 2009).

Esse micro-organismo apresenta várias características que justificam a sua resistência antimicrobiana, entre elas, citam-se as alterações nas proteínas ligadoras de penicilinas, a perda ou diminuição na expressão de proteínas de membrana externa, a hiperexpressão de bombas de efluxo e a produção de beta-lactamases (HIGGINS et al., 2004).

Dentre os fatores de risco que o paciente é exposto, os principais, associados à Infecção por Acinetobacter spp, são: ventilação mecânica, presença de sonda nasogástrica, cateter 
arterial e a permanência prolongada na UTI. Outro fator importante é o uso prolongado e irrestrito de antimicrobianos, como as penicilinas, cefalosporinas e aminoglicosídeos (LUZ, 2010).

Desse modo, considerando a importância clínica da bactéria em questão, o presente trabalho teve como objetivo realizar um levantamento epidemiológico da prevalência de Acinetobacter spp isolada de pacientes internados em hospitais de São José dos Campos, a partir de 5.759 amostras de hemoculturas, no período de agosto de 2012 a agosto de 2013, por meio da análise dos resultados dos exames microbiológicos, realizados por um laboratório de análises microbiológicas de São José dos Campos.

\section{MATERIAIS E MÉTODOS}

A presente pesquisa foi aprovada pelo Comitê de Ética/UNIVAP, sob protocolo 25078513.4.0000.5503. Esse estudo foi um levantamento epidemiológico (estudo epidemiológico descritivo transversal) que pretendeu determinar a prevalência da bactéria do gênero Acinetobacter spp em 5.759 amostras de hemoculturas, oriundas de pacientes com bacteriemia internados em hospitais públicos de São José dos Campos - SP. Os resultados das hemoculturas foram fornecidos por um laboratório de análises microbiológicas, envolvendo o período de agosto de 2012 a agosto de 2013.

Os critérios de inclusão foram: resultados laboratoriais já liberados de pacientes adultos, na faixa etária entre 18 a 98 anos, de ambos os gêneros. Os resultados das hemoculturas foram cedidos pelo laboratório, por meio de uma tabela, onde não houve a identificação do paciente. Os pesquisadores tiveram acesso aos seguintes dados: idade, gênero e os microorganismos isolados.

\section{RESULTADOS}

Durante o período estudado nesta pesquisa, de 01 de agosto de 2012 a 01 de agosto de 2013, foram realizados um total de 5.759 exames de hemoculturas, nos quais 1.019 tiveram resultados positivos. O Gráfico 1 mostra a distribuição dos patógenos isolados nas hemoculturas, por quantidade de amostras. 
Gráfico 1 - Patógenos encontrados em hemoculturas de pacientes internados em hospitais de São José dos Campos, no período de 01 de agosto de 2012 a 01 de agosto de 2013.

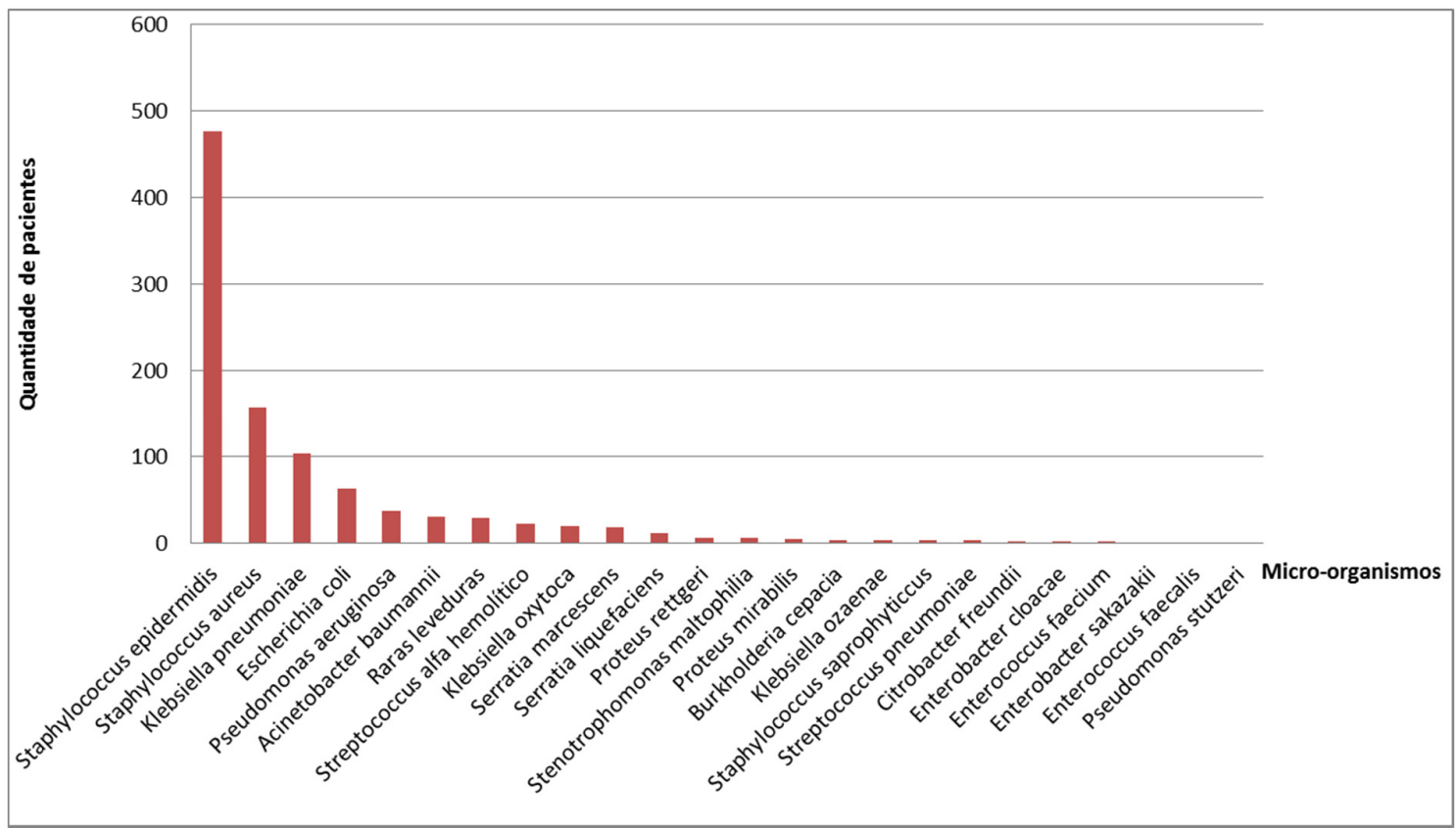

Entre os patógenos isolados, a bactéria Acinetobacter baumannii foi o sexto patógeno mais encontrado nas hemoculturas, representando $3,04 \%(n=31)$ dos resultados positivos.

O Gráfico 2 apresenta a frequência de $A$. Baumannii entre os gêneros. Dentre os 31 resultados positivos de $A$. baumannii, 23 das amostras eram de pacientes do gênero feminino e 8 do masculino, representando $74,2 \%$ e $25,8 \%$, respectivamente.

Gráfico 2 - Distribuição por gêneros dos pacientes (1: feminino; 2: masculino) internados em hospitais de São José dos Campos, com hemocultura positiva para Acinetobacter baumannii, no período de 01 de agosto de 2012 a 01 de agosto de 2013

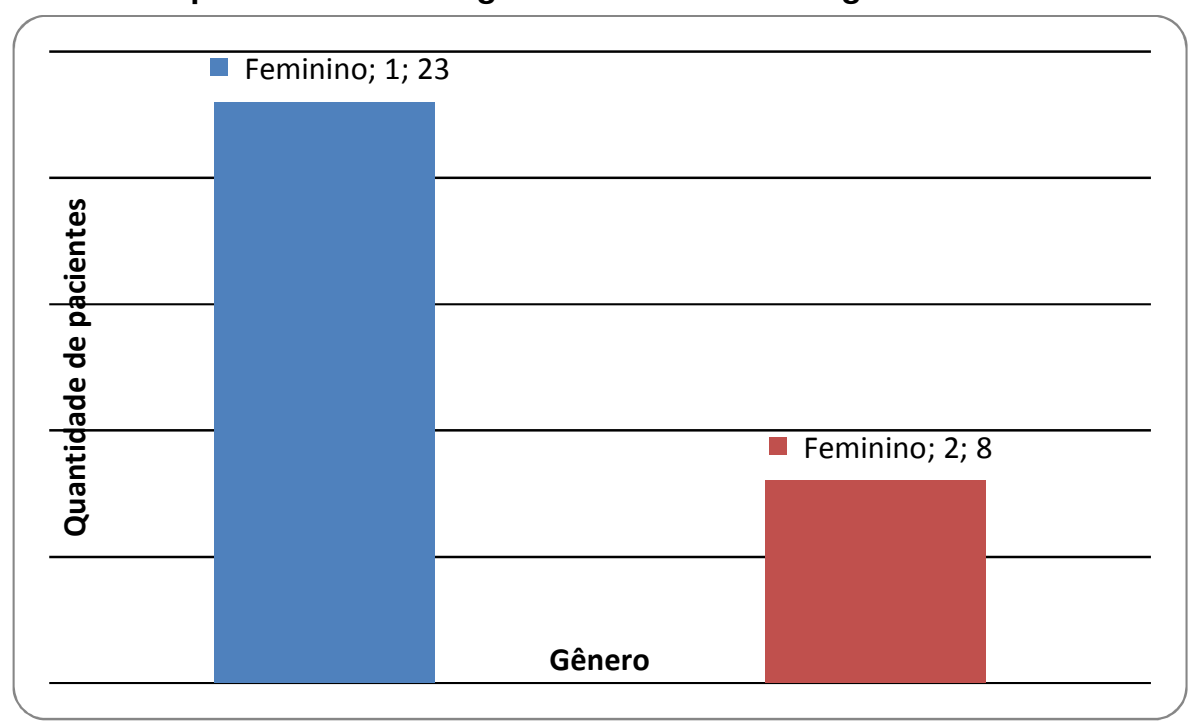


No Gráfico 3, pode-se observar a distribuição por faixa etária das hemoculturas positivas para $A$. baumannii, abrangendo pacientes de 0 a 98 anos. Entre eles, a faixa etária que teve a maior incidência, desse micro-organismo, foi a de 51-70 anos (média de 56 anos), representando $38,7 \%$ das amostras estudadas.

Gráfico 3 - Distribuição por faixa etária dos pacientes internados em hospitais de São José dos Campos, com hemocultura positiva para Acinetobacter baumannii, no período de 01 de agosto de 2012 a 01 de agosto de 2013.

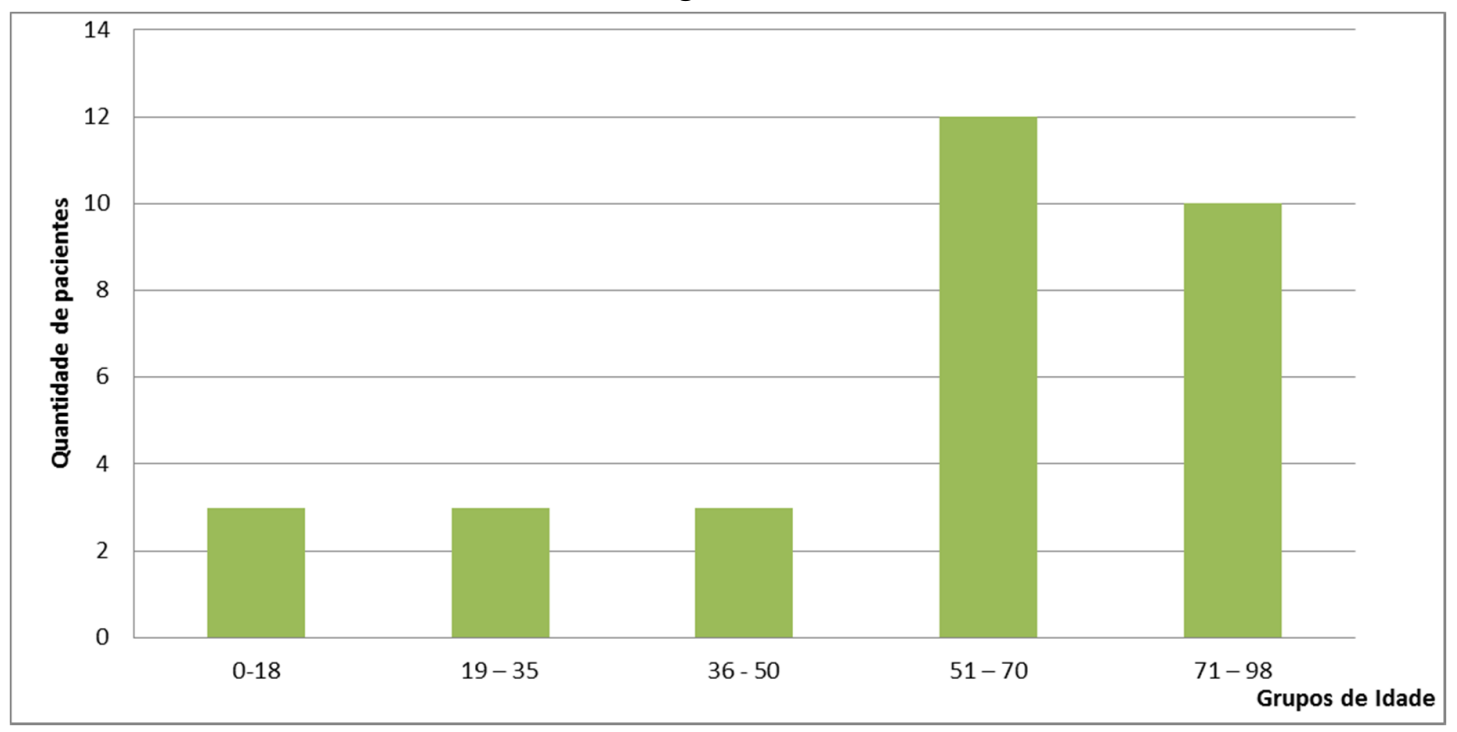

\section{DISCUSSÃO}

No presente estudo, foi observado que Acinetobacter baumannii foi o sexto patógeno mais encontrado em exames de hemoculturas de pacientes atendidos por laboratório de São José dos Campos, durante o período de 01 de agosto de 2012 a 01 de agosto de 2013; representando um total de $3,04 \%$ dentre os valores positivos. Observou-se que, para os resultados positivos para $A$. baumannii, foi encontrada uma predominância do gênero feminino, com $74,2 \%$ das amostras. Em relação à faixa etária, aqueles que se encontravam no grupo de 51 a 70 anos apresentaram maior isolamento desse micro-organismo em hemocultura, representando $38,7 \%$ do total dos pacientes.

Luz (2010), em um estudo realizado no Projeto SCOPE Brasil, que foi uma extensão de um estudo norte-americano, analisou 1.787 amostras oriundas de diversos estados brasileiros, abrangendo todas as regiões, e foi observado que os bacilos Gram negativos foram responsáveis por $62,2 \%$ das infecções na corrente sanguínea, enquanto que os cocos Gram positivos, por 32\%. Dentro dos micro-organismos isolados, a Klebsiella pneumoniae foi o patógeno mais encontrado (14,9\%) e a bactéria Acinetobacter baumannii ocupou a terceira posição (11,8\%; n=272). Diferentemente, no nosso trabalho, de 1.019 hemoculturas positivas, os micro-organismos mais isolados foram cocos Gram positivos, Staphylococcus epidermidis 
$(\mathrm{n}=477)$ e $S$. aureus $(\mathrm{n}=158)$, seguido por bacilos Gram negativos, Klebsiella pneumoniae $(n=103)$, Escherichia coli $(n=63)$, Pseudomonas aeruginosa $(n=35)$ e A. baumannii $(n=31)$.

Um estudo realizado por Costa (2009) mostrou que, no período entre 1993 a 1994, Acinetobacter spp foi responsável por $15 \%$ das infecções na corrente sanguínea, dentro do Hospital das Clínicas de São Paulo. Esse mesmo estudo constatou que, no ano de 2006, o hospital apresentou tal patógeno como o segundo agente etiológico mais frequente nas unidades de terapia intensiva.

Vincent et al. (2009), em um estudo mundial, utilizaram dados de 75 países, abrangendo 1.265 UTIs (14.414 pacientes), sendo que 667 se localizavam na Europa Ocidental, 210 na América Central e América do Sul, 137 na Ásia, 97 na Europa Oriental, 83 na América do Norte, 54 na Oceania, e 17 na África. Desse total, 9\% dos pacientes estavam infectados por Acinetobacter spp.

Sunenshine et al. (2007) realizaram um estudo coorte, analisando os registros de pacientes atendidos entre janeiro de 2003 a agosto de 2004, em dois hospitais localizados na cidade de Baltimore. Entre eles, um total de 166 pacientes apresentou resultado positivo para Acinetobacter spp, e 96 (58\%) apresentaram uma multirresistência às drogas. O isolamento desse micro-organismo se deu a partir de infecções respiratórias $(50 \%)$, de infecções da corrente sanguínea (31\%), e de feridas cirúrgicas, trato urinário, entre outros sítios estéreis $(19 \%)$.

Sabemos que a bacteriemia é de grande preocupação para a saúde pública, pois $A$. baumannii está associada a altas taxas de multirresistência aos antibióticos, podendo causar considerável morbidade e mortalidade, elevando os custos do tratamento. Existem tentativas de interrupção da transmissão da bactéria, porém, estas devem ser tomadas em conjunto; como, por exemplo, reforço de normas de controle e prevenção de infecções, higienização das mãos dos funcionários, limpeza completa e desinfecção, culturas de vigilância ativas, isolamento de pacientes contaminados, entre outros (ELIOPOULOS et al., 2008). Essas medidas são necessárias para que se evite a transmissão da multirresistência entre o gênero Acinetobacter.

\section{CONCLUSÃO}

A análise dos dados levantados em exames de hemocultura, em São José dos Campos, revelou uma quantidade expressiva de $A$. baumannii durante o período de um ano de estudo.

Entre os patógenos isolados, a $A$. baumannii se encontrava na sexta posição, em 31 amostras de um total de 1.019 exames. A incidência foi maior no gênero feminino e na faixa etária entre 51 a 70 anos. 


\section{REFERÊNCIAS}

COSTA, S. F. Estudo dos mecanismos de resistência de isolados de Acinetobacter spp. de sangue resistentes aos carbapenens. 2009. Disponível em: $<$ http://www.bv.fapesp.br/pt/auxilios/23913/estudo-dos-mecanismos-de-resistência-deisolados-de-acinetobacter-spp-de-sangue-resistentes-aos-carb/>. Acesso em: 04 dez. 2013.

ELIOPOULOS, G. M. et al. Acinetobacter baumannii: epidemiology, antimicrobial resistance, and treatment options. Clinical infectious diseases, v. 46, n. 8, pp. 1254-1263, 2008.

FIGUEIREDO, D. Q. et al. Detection of metallo-beta-lactamases in hospital strains of Pseudomonas aeruginosa and Acinetobacter baumannii. Jornal Brasileiro de Patologia e Medicina Laboratorial, v. 45, n. 3, pp. 177-184, 2009.

HIGGINS, P. G. et al. Selection of topoisomerase mutations and overexpression of adeB mRNA transcripts during an outbreak of Acinetobacter baumannii. Journal of Antimicrobial Chemotherapy, v. 54, n. 4, pp. 821-3, 2004.

LEVY, C. E. et al. Manual de microbiologia clínica aplicada ao controle de infecção hospitalar. São Paulo: Associação Paulista de Estudos e Controle de Infecção Hospitalar, 2004. 189p.

LUZ, A. P. F. Acinetobacter spp resistente a antimicrobianos carbapenêmicos isolados de infecções hospitalares de corrente sanguínea: estudo do projeto SCOPE Brasil. 2010. 76f. Dissertação (Mestrado) - Universidade Federal de São Paulo, São Paulo, 2010.

PORTER, R. S. et al. The merck manual home health handbook. White House Station, EUA: Merck Research Laboratories, 2009. 2. 165p.

RUNGRUANGHIRANYA, S.; CHARURAT, S.; TERMKIAT, K. Acinetobacter infection in the intensive care unit. Journal of Infectious Diseases and Antimicrobial Agents, v. 22, n. 2, pp. 77-92, 2005.

SUNENSHINE, R. H. et al. Multidrug-resistant Acinetobacter infection mortality rate and length of hospitalization. Emerging Infectious Diseases, v. 13, n. 1, pp. 97-1003, 2007.

VINCENT, J. L. et al. International study of the prevalence and outcomes of infection in intensive care units. JAMA: The Journal of the American Medical Association, v. 302, n. 21, pp. 2323-2329, 2009. 